\title{
A numerical methodology for thermo-fluid dynamic modelling of tyre inner chamber: towards real time applications
}

\author{
Luigi Teodosio - Giuseppe Alferi • Andrea Genovese (D) Flavio Farroni • \\ Benedetto Mele $\cdot$ Francesco Timpone $\cdot$ Aleksandr Sakhnevych
}

Received: 1 April 2020/ Accepted: 15 January 2021 / Published online: 2 February 2021

(C) The Author(s) 2021

\begin{abstract}
The characterization and reproduction of tyre behaviour for vehicle modelling is a topic of particular interest both for real-time driver in the loop simulations and for offline performance optimization algorithms. Since the accuracy of the tyre forces and moments can be achieved by the accurate physical modelling of all the phenomena concerning the tyreroad interaction, the link between the tyre thermal state and the tyre frictional performance turns into a crucial factor. An integrated numerical methodology, allowing to couple the full 3D CFD (Computational Fluid Dynamics) flux within the internal chamber of the tyre with an equivalent discrete 3D structure model, is proposed with the aim to completely represent the tyre thermodynamic convective behaviour in the steady-state operating conditions. 3D CFD model enables the evaluation of the internal distribution of the gas temperature and of the thermal powers exchanged at each sub-wall in detail. This allows to increase the reliability of the tyre thermodynamic modelling with a particular reference to the proper managing of the aero-thermal flow of the brake disc impact on the rim temperature and therefore on the internal gas dynamics in terms of temperature and pressure, being able to optimize the tyre overall
\end{abstract}

L. Teodosio · G. Alferi · A. Genovese $(\bowtie)$.

F. Farroni - B. Mele · F. Timpone - A. Sakhnevych Department of Industrial Engineering, University of Naples Federico II, Via Claudio 21, 80125 Naples, Italy

e-mail: andrea.genovese2@unina.it dynamic performance in both warm-up and stabilized thermal conditions. The steady RANS (Reynolds Averaged Navier-Stokes) simulations have been performed employing the 3D CFD model in a wide range of angular velocities with the aim to calculate the convective thermal flux distributions upon rim and inner liner surfaces. The simulation results have been then exploited to derive the convective heat transfer coefficients per each sub domain to be employed within the real-time tyre physical thermal model, with the peculiar advantage of an enhanced model reliability for thermal characteristics. To validate the proposed methodology, the tyre thermal model outputs, in terms of temperatures of internal and external layers, have been validated towards the acquired ones within the specific routine performed on tyre force and moment test bench, confirming an excellent agreement with the experimental data in the entire range of operating conditions explored.

Keywords Tyre thermodynamics - 3D CFD . Numerical procedure

\section{Introduction}

In the last decades, tyres acquired a fundamental role in the motorsport and automotive industry, since the optimization of their behaviour in different operating conditions and for diverse use scenarios represents a 
key-factor for the achievement of the optimal overall performance [1-4].

With the rise of the autonomous driving and more sophisticated on-board control logics, due to the growing need to reproduce vehicle dynamics behaviour with the highest level of accuracy at the lowest possible cost, the vehicle modelling and simulation tools concerning the understanding and the reproduction of the tyre-road interaction phenomena have acquired a significant weight [4, 5]. From the modelling point of view, the research effort has been therefore addressed to the modelling and estimation of all those quantities not directly acquirable even with the state of art sensing technology, but which could represent a key factor in the continuous improvement of control algorithms and logics to be employed in the increasing expansion of interconnected and smart vehicles [4-8]. Different approaches for modelling the tyre thermomechanical behaviour can be found in literature [9-13] as well as various practical case studies $[3,14-16]$, which testify the attention payed to the topic.

In this scenario, the development of predictive realtime physical models, able to provide the real-time onboard estimation of the tyre compound bulk temperature, linked with the tyre dynamic behaviour in terms of grip and stiffness variations, is an important task $[17,18]$. Furthermore, these models have to be full three-dimensional, taking into account of the composite tyre structure, rim geometry and peculiar sidewalls' characteristics. It is absolutely necessary to consider all the geometric and material properties, since the behaviour of the tyre is highly non-linear with the applied forces, velocity, pressure and wheel alignment effects. Even only considering the dynamic contact patch, where the friction power generative term and the conduction between the tyre and the road occur, the distribution of the temperature is deeply affected on the contact patch geometry in the particular operating dynamic and kinematic conditions under analysis, resulting in possible significant temperature gradient along the tire width direction. The same can be argued for the local deformation distribution within the tyre inner layers, resulting in specific local heating distributions within the meshed threedimensional domain. Starting from the TRT thermodynamic model, with its applications for both the performance optimization in racing field and in advanced control logics development for passenger vehicles, the physical modelling of the tyre behaviour can become particularly useful for the understanding of the tyre ideal working range and for the evolution of the control systems actions in emergency situations, thanks to the enriched dynamic vehicle state due to the availability of additional physical variables $[19,20]$.

To run at the maximum performance level, a key area of development in top-ranking motorsport categories concerns the tyre management within the optimal temperature/pressure conditions, properly employing rim heating techniques. The thermal energy generated from the brakes is transferred to the wheel rim via radiation mechanism, increasing the temperature and pressure of the internal air and the temperature of the tyre compound. In each manoeuvre, a specifically designed wheel assembly, consisting of the braking system, rim and cooling ducts, is able to optimize the airflow dynamics, getting proper aerodynamics (in terms of downforce and drag reduction) and to heat up differently in the diverse phases of the race.

In such scenario, the modelling of the convective heat transfer for the tyre system is a relevant topic, as evidenced by the large number of articles on the subject [21-24]. Indeed, an accurate prediction of tyre thermal flow allows a proper monitoring and control of the air pressure and temperature variations in the tyre inflation chamber. This aspect is particularly relevant during all the stages of a race to manage both the tyre friction and viscoelastic hysteresis, also taking into account the unsteady operating conditions experienced by the tyre.

Three dimensional CFD (Computational Fluid Dynamics) modelling of tyre system, providing a full description of both the thermal and fluid-dynamic flow fields, is probably the most reliable method for an accurate prediction of convective heat transfer rates in the tyre system. This approach allows to evaluate the tyre thermal performance in both steady-state and unsteady operating conditions. Accurate CFD modelling provides highly reliable results also in complex three-dimensional flows $[25,26]$, but they require a significant computational cost, mostly depending on the resolution of the adopted mesh. Also, the kind of analysis can heavily affect the computational effort, in particular when unsteady conditions need to be analysed. On the contrary, the convective modelling based on 0D/1D (zero or one dimensional) approaches require a lower computational effort for both steady 
and unsteady conditions. Even if a computational benefit derives by the adoption of $0 \mathrm{D} / 1 \mathrm{D}$ convective approaches, their reliability mostly depends on the effective description of the overall tyre internal chamber; in this case, some improvements are needed aiming to describe in details peculiar thermal effects. A reliable methodology can help to obtain a 3D tire model enhanced from a thermal point of view. This allows the development of an efficient tool to be integrated within a driving simulator platform, adopted by vehicle manufacturers to perform realtime simulations oriented to $R \& D$ and product development activities.

In the present paper a hierarchical integrated numerical procedure is adopted for the first time for the tyre thermal study. The integration of different numerical procedures has been already employed in the fluid-dynamic field, especially for turbulent flows [27-29] which play a significant role in thermal studies. In this work, the relevant thermal parameters computed by a full 3D CFD model of tyre internal chamber are used in the fully described 3D wheel thermal model with the specific purpose of describing the tyre thermodynamic convective behaviour in realtime. The proposed mixed methodology allows to properly combine the advantages of two single modelling approaches. In the specific case under study, a unique zero-value of camber angle has been considered in pure rolling conditions, resulting in an exceptional operating condition where the tyre could be also described in terms of an elastic ring, or of the 1D model along the radial direction. Although, the authors intend to extend the study in the further works approaching wider conditions with different values of camber angle and interaction forces applied.

The paper is organized in four more sections in addition to the introduction. The second section deals with a deep description of the physical phenomena governing the tyre dynamic behaviour. The third and fourth sections report the 3D CFD and the reduced 1D convective model integrated within the tyre thermal model, respectively. They are coupled within the proposed numerical methodology, which provides a data transfer scheme from 3D model to the 1D convective model. The fifth section presents a description of the experimental tyre tests using the force and moment Flat-Trac bench and the validation of the full tyre thermal model through the comparison of the experimental outcomes with the simulated ones, in terms of temperatures of several inner tyre layers. Finally, the last section regards the conclusions and some comments on the future developments of this research activity.

\section{Tyre dynamic behaviour}

The working temperature and pressure of a tyre depend on several aspects, as the viscoelastic characteristics of the compound, ambient temperature, internal pressure, tread wear level, peculiar structural materials, but also, of course, on the vehicle setup and driver behaviour [14, 30]. Tyre composite structure consists of tread compound, working together with the belt system and tyre casing, to achieve traction and cornering capabilities [31].

The effects of tyre temperature and pressure on its dynamic characteristics and friction coefficient are illustrated in the Fig. 1. The inflation pressure is one of the crucial factors to be taken into account in order to properly manage the tyre dynamics, since it governs not only the contact patch in terms of both area extension and shape, but also modifies the tyre structural characteristics, including the sidewall rigidity, and, therefore, the radial, braking and cornering tyre stiffnesses.

Furthermore, as illustrated in the Fig. 2, the internal pressure is also accountable for the tyre hysteretic behaviour: the Strain Energy Loss factor mainly depends on the induced loads' excitation frequency acting on the wheel during the operating conditions and the tyre internal pressure.

The inflation pressure governs also the hysteretic behaviour of the tyre, which deeply depends on the materials constituting the tyre structure and on the chemicals and additives mixed in the rubber compound. Moreover, as regards the tyre performance in terms of friction coefficient arising between the tread polymers and the road texture, it can be considered as due to at least three different phenomena [32, 33]:

$F_{T}=F_{A}+F_{H B}+F_{W}$

where

- $F_{T}$ is the total friction coefficient,

- $F_{A}$ is the adhesive term due the Van der Waals' forces between the two surfaces in contact at the molecular level, 

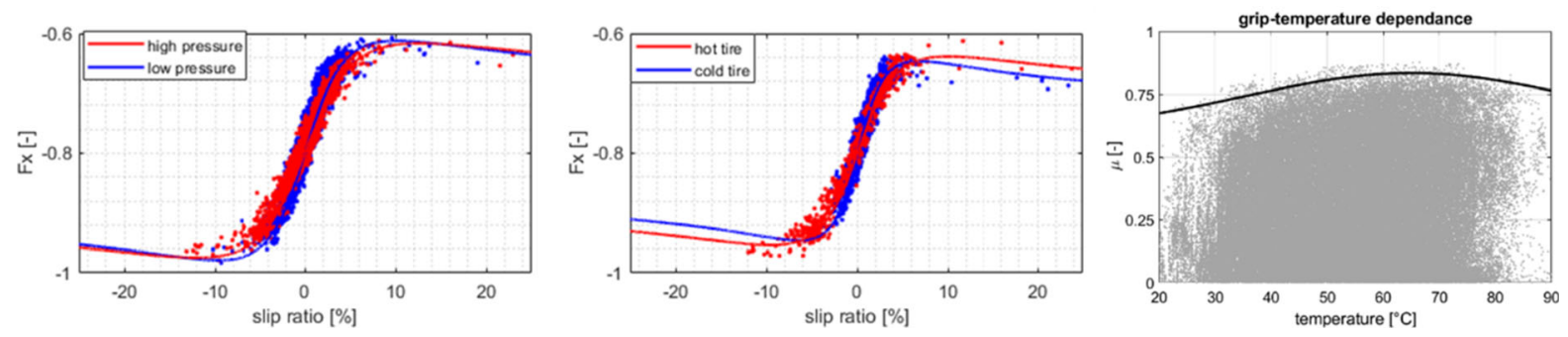

Fig. 1 Tyre friction coefficient and dynamic stiffnesses' dependencies towards temperature and pressure
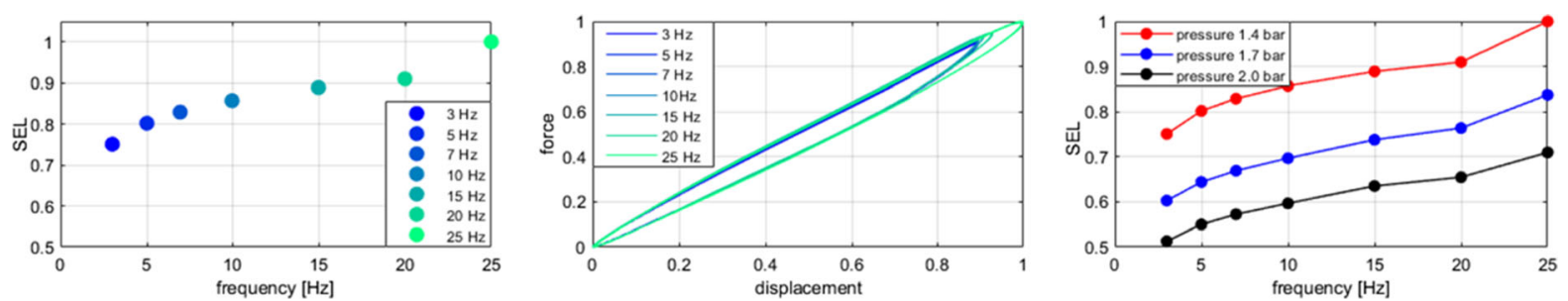

Fig. 2 Tyre hysteretic behaviour dependence in terms of inflation pressure and load frequency

- $F_{H B}$ is the hysteretic term due to the compound bulk deformation hysteresis within the rubber,

- $F_{W}$ is the contribution due to the removal of the rubber material during the tyre life (can be assumed negligible since it seems to weigh no more than $2 \%$ ).

The adhesive and the hysteretic terms are not independent because as the adhesion increases the extension of the contact area, the zone affected by hysteretic deformations grows too [34].

Since all the physical phenomena governing the tyre behaviour are deeply interconnected, the characterization of the tyre behaviour is particularly complex and delicate: the tyre forces demonstrate a highly nonlinear dependence on slip ratio, slip angle, camber angle, vertical load, inflation pressure, wear level, internal and external temperature distributions and, obviously, on the tyre structural characteristics $[35,36]$.

For such reason, a reliable and predictive tyre physical model has to involve a large amount of effects, useful to take into account that:

- During the life cycle, the tyre deeply modifies its dynamic behaviour in relation to the progressive application of the cumulated history of operating/ load conditions. A progressively reduced grip level extends the stopping distance of vehicles and can result in vehicle instability and risk of blowout failure [37]. Therefore, the overall goal of tyre design should consist in the optimal exploitation of its dynamic potential in every vehicle working conditions during the entire lifecycle, leading to achieve both the optimal performance and the safety requirements accurately designed rim solutions permit to handle the airflow allowing to manage the rim temperature, which in-turn influences the tyre tread core temperature. A proper transport term of the airflow between the brake assembly and the wheel rim, becomes so important for tyre performance and durability purposes. Therefore, the ability to represent the tyre air flow inside the wheel chamber becomes of primary importance, especially in co-simulation environments where different systems are interacting each other, to correctly transfer heat from the rim surface to the tyre inner one.

\section{CFD model}

A tyre in cruise condition with constant speed and nominal vertical load has been taken into account. In such conditions the tyre can be described by an undeformed geometry with good approximation. Thus, a CAD (Computer Aided Design) model of the undeformed tyre has been made with typical 
dimensions of a large passenger car. In Table 1 the details of the tyre geometry are reported.

A hybrid mesh with a refinement at the walls has been generated inside the tyre model; it counts about 4 million cells in the finest level and complies with mesh requirements in terms of aspect ratio (ratio between two main cell dimensions), skewness (cell degeneration from the equilateral cell) and y + (dimensionless wall distance of the first inner point) to allow accurate and stable 3D numerical simulations. The adoption of a hybrid mesh is due to the design of CFD software whose algorithms are better calibrated for unstructured mesh. In Fig. 3 a detail of the adopted CFD mesh is shown, it also reports a 'zoom' of the mesh refinement at wall boundary (the different grey shading in the figure is due to a spatial rendering effect due to lighting). In Fig. 4 the wall $y+$ distribution is reported showing that it is below one almost everywhere ensuring a proper resolution of the boundary layer. The wall $y+$ is the wall distance of the first inner point in wall variables defined as: $\mathrm{y}+=\rho_{\mathrm{w}} \mathrm{u}_{\tau} \mathrm{y} / \mu_{\mathrm{w}}$, where $\rho_{\mathrm{w}}$ is the density at the wall, $\mathrm{u}_{\tau}$ the friction velocity (square root of the ratio between shear stress and the density at the wall) and $\mu_{\mathrm{w}}$ the dynamic viscosity at the wall. It is a measure of the quality of the grid near the wall and when it is around or below one the grid resolution near the wall is sufficient to accurately resolve the near wall flow field.

Steady Reynolds Averaged Navier-Stokes (RANS) simulations have been performed by using the flow solver fluent ANSYS, widely adopted in engineering and research framework [38, 39]. The RANS equations are derived by the Navier-Stokes equations performing a time averaging, the resulting equations contain an additional unknown term that must be

Table 1 Main geometrical data of the tyre model

\begin{tabular}{ll}
\hline Tyre geometry & \\
\hline Inner liner radius & $320 \mathrm{~mm}$ \\
Rim radius & $220 \mathrm{~mm}$ \\
Inner liner width & $310 \mathrm{~mm}$ \\
Rim width & $279 \mathrm{~mm}$ \\
Inner liner area & $0.664 \mathrm{~m}^{2}$ \\
Rim area & $0.410 \mathrm{~m}^{2}$ \\
Sidewall area & $0.108 \mathrm{~m}^{2}$ \\
\hline
\end{tabular}

modelled adopting some approximations that leads to the turbulence modelling. Since there are no deflection (the tyre is undeformed), the incompressible solver has been used with coupled pressure-velocity formulation that is the most accurate method in solving the pressure-velocity field in an incompressible solver.

The K- $\omega$ SST (Shear Stress Transport) turbulence model [40] has been adopted and second order numerical schemes have been set both for the flow field equations and turbulence model equations. The incompressible ideal gas model has been used to take into account possible natural convection effects at low tyre rotational speeds. Indeed, the model allows (small) variation of density due to variations of temperature such as in natural convection case. It computes the density as: $\rho=\mathrm{p}_{0} /\left(\mathrm{RT} / \mathrm{M}_{\mathrm{W}}\right)$, where $\rho$ is the density, $\mathrm{R}$ the universal gas constant, $\mathrm{M}_{\mathrm{W}}$ the molecular weight of the gas, $\mathrm{P} 0$ the operating pressure. Thus, the model differs from the ideal gas model since the density variations are linked only temperature variations. An initial operative pressure of $0.2 \mathrm{MPa}$ has been assigned. A moving wall boundary condition and a constant temperature have been set at the walls.

In particular, temperature at wall boundaries is not evaluated by a FE (finite element) model of tyre structure, coupled to the CFD model. Constant temperatures have been assigned at each wall surface; temperature levels have been differentiated for innerliner, rim and side-wall surfaces, basing on the available experimental data for the examined tyre. More details about the 3D CFD model meshing and setup can be found in previous authors' works [27, 28, 41, 42]. In Table 2 the case studies at different angular velocities are reported, while in Table 3 the temperatures at the walls are shown representing the typical average wall temperatures of a passenger tyre. The results of $3 \mathrm{D}$ numerical simulations will be presented in the following section.

\subsection{CFD results}

CFD analyses are performed with the aim to characterize the thermal behaviour of the tyre, deriving the 3D-related convective heat transfer coefficients of both inner liner and rim to be implemented in a 1D tyre thermal model, already developed by the authors in the recent years [19, 20].

A convergence analysis aimed to reduce the mesh size has been first performed. In Fig. 5 the computed 


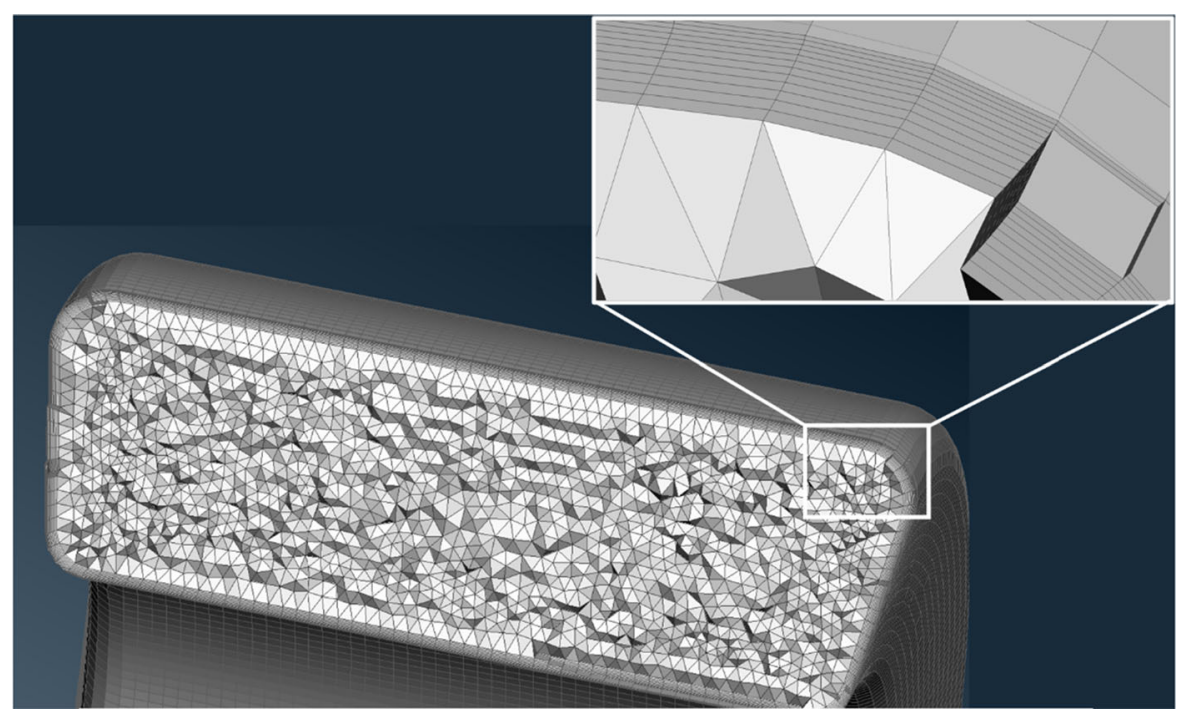

Fig. 3 Detail of the hybrid CFD mesh inside the tyre cross section with refinement at the walls

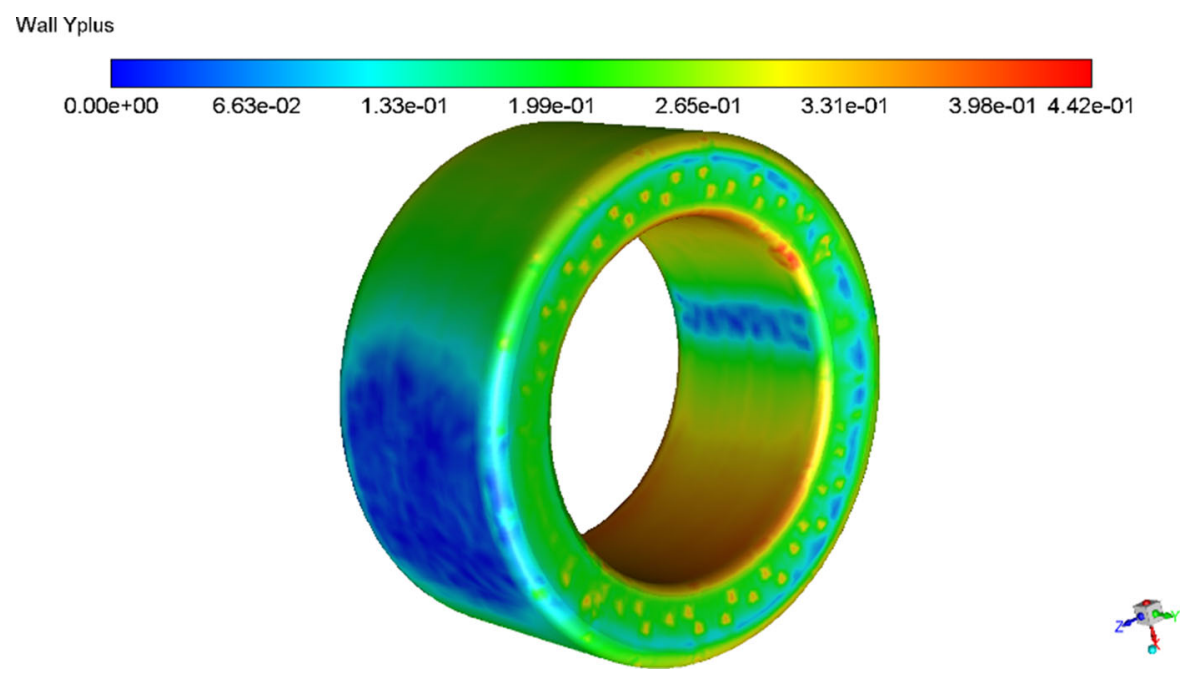

Fig. 4 Wall y + (dimensionless wall distance) distribution on the tyre

heat transfer coefficients and the total thermal powers of inner line and rim for three grid levels are reported for the case at $\omega=37,5 \mathrm{rad} / \mathrm{s}$, level 1 refers to the finest grid level. In particular, grid level 1, 2 and 4 correspond to a mesh composed by 13, 4 and 2 million of total cells respectively. The convergence while reducing the mesh size shows that the adopted grid level 2 returns a good accuracy and will be used in the following analyses.

As discussed in the previous section, numerical analyses are carried out in steady-state conditions at different angular velocities of the tyre. In Fig. $6 a, b$ and $\mathrm{c}$, the convergence of average gas temperature, total thermal powers of inner liner, rim and sidewalls and of the related convective heat transfer coefficients are plotted in the case of the highest tyre angular velocity $(\omega=187.5 \mathrm{rad} / \mathrm{s})$. The figures show that also in the more complex case the solution is convergent.

In Table 4, the computed thermal powers of the tyre sub-domains are shown. A null net thermal power is reached for tyre domain, highlighting the thermal equilibrium condition achieved in the steady-state operation. It is worth noting that the exchange thermal 
Table 2 Case studies at different tyre angular velocities

\begin{tabular}{ll}
\hline Case number & Angular velocity $(\mathrm{rad} / \mathrm{s})$ \\
\hline 0 & 0 \\
1 & 18.75 \\
2 & 37.50 \\
3 & 56.25 \\
4 & 75 \\
5 & 93.75 \\
6 & 112.50 \\
7 & 131.25 \\
8 & 150.00 \\
9 & 168.75 \\
10 & 187.50 \\
\hline
\end{tabular}

Table 3 Imposed wall temperatures of tyre model

\begin{tabular}{lc}
\hline Imposed temperatures $(\mathrm{K})$ \\
\hline Inner liner & 363 \\
Rim & 323 \\
Sidewall SX & 343 \\
Sidewall DX & 343 \\
\hline
\end{tabular}

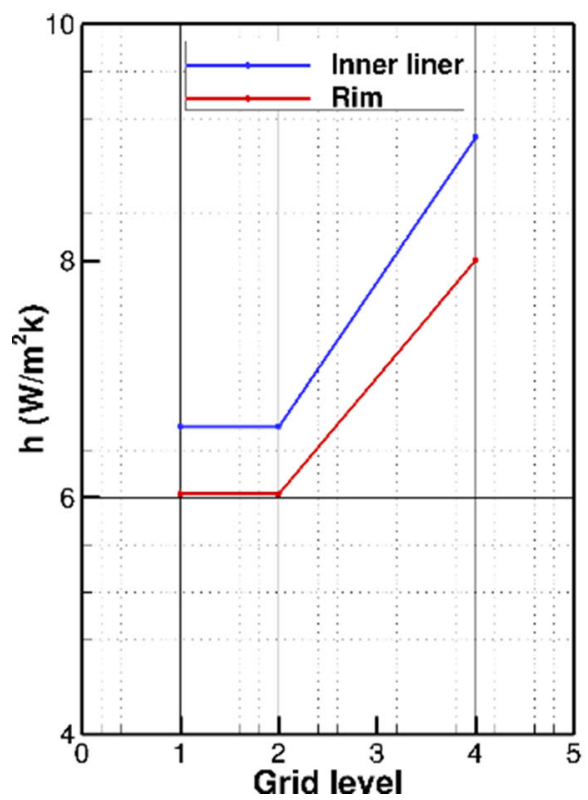

Fig. 5 Tyre RANS simulations: grid dependency analysis powers by tyre sidewalls are substantially negligible with respect to inner liner and rim parts.

A null angular velocity has been also considered to analyse the case where a natural convection mechanism can be established within the tyre system and a reduced heat exchange with the external environment is expected to occur. Figure $7 \mathrm{a}$ and $\mathrm{b}$ show the temperature and velocity contours in a cross section of the tyre, while a detail of $3 \mathrm{D}$ velocity vector distribution in a longitudinal tyre section is reported in Fig. 8.

It can be seen from Fig. 7a that the temperature difference between the tyre surfaces, located at maximum and minimum radial distance from the tyre rotational axis, induces a small natural convection motion within the tyre.

While increasing the angular velocity of the tyre, the natural convection mechanism is overcome by the forced convection mechanism induced by the tyre rotation. In these conditions, a greater thermal power can be exchanged mainly due to the internal tyre air flow conditions. This is shown in the following Figs. 9 and 10 , where the velocity contours in cross and longitudinal tyre sections and 3D velocity vector

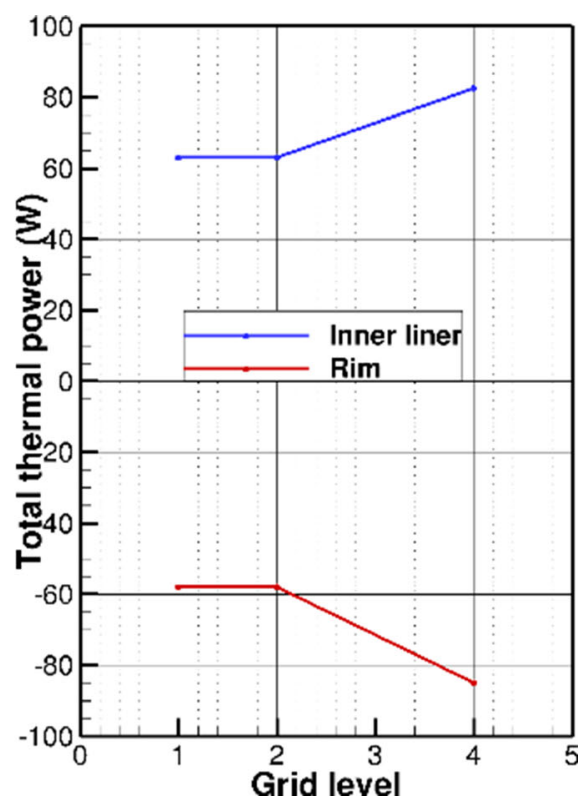



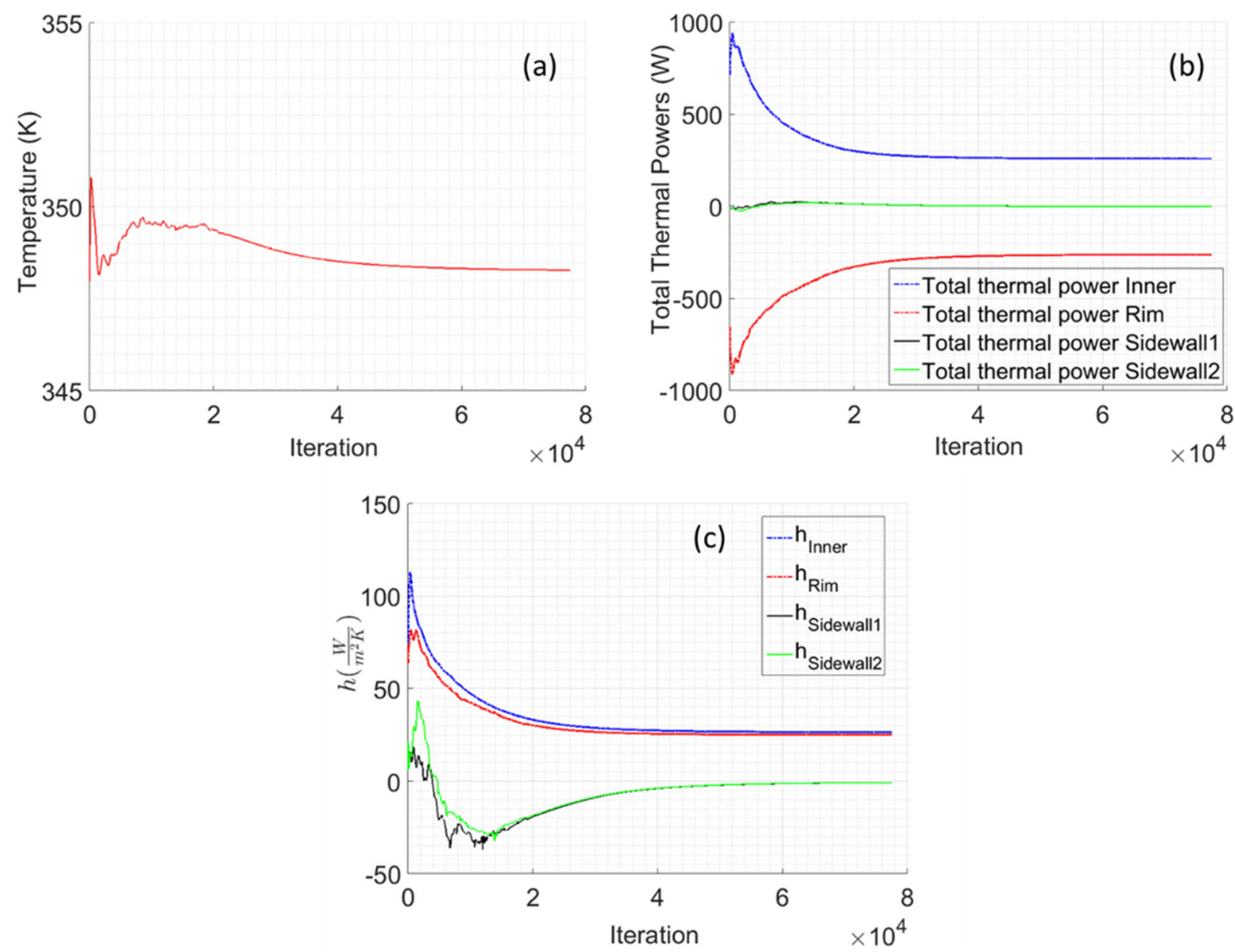

Fig. 6 Tyre RANS simulation at $\omega=187,5 \mathrm{rad} / \mathrm{s}$. Convergence of average temperature (a), thermal powers (b) and convective heat transfer coefficients $(\mathbf{c})$

Table 4 Tyre RANS simulation at $\omega=187,5 \mathrm{rad} / \mathrm{s}$. Thermal powers of tyre sub-domains

\begin{tabular}{lc}
\hline Walls & Thermal powers(W) \\
\hline Inner liner & 260.49 \\
Rim & -262.22 \\
Sidewall1 & -0.86 \\
Sidewall2 & -0.86 \\
Overall wall & $5.53 \mathrm{E}-4$ \\
\hline
\end{tabular}

distribution are respectively displayed in the case of the highest angular velocity $(\omega=187.5 \mathrm{rad} / \mathrm{s})$.

In these conditions the flow field inside the tyre is substantially characterized by an increasing velocity along the radial direction induced by the imposed tyre rotation.
It is worth remarking that a reliable prediction of the flow field inside tyre represents a fundamental prerequisite to furnish the actual thermal state of tyre. The results presented in the Fig. 9 and Fig. 10 can be considered consistent with the physical expectations and the related 3D model can be employed to reproduce the variations of thermal power under rotating boundary conditions. The purpose of Fig. 10 is to show how at high rotational velocity the gas effectively rotates with the rim and the natural convection is negligible, confirming the reliability of the model.

3D steady simulations at different angular velocities allow to derive the total thermal powers and the convective heat transfer coefficient profiles for both inner liner and rim, representing the tyre parts that are mostly interested in the heat exchange. Figure 11 

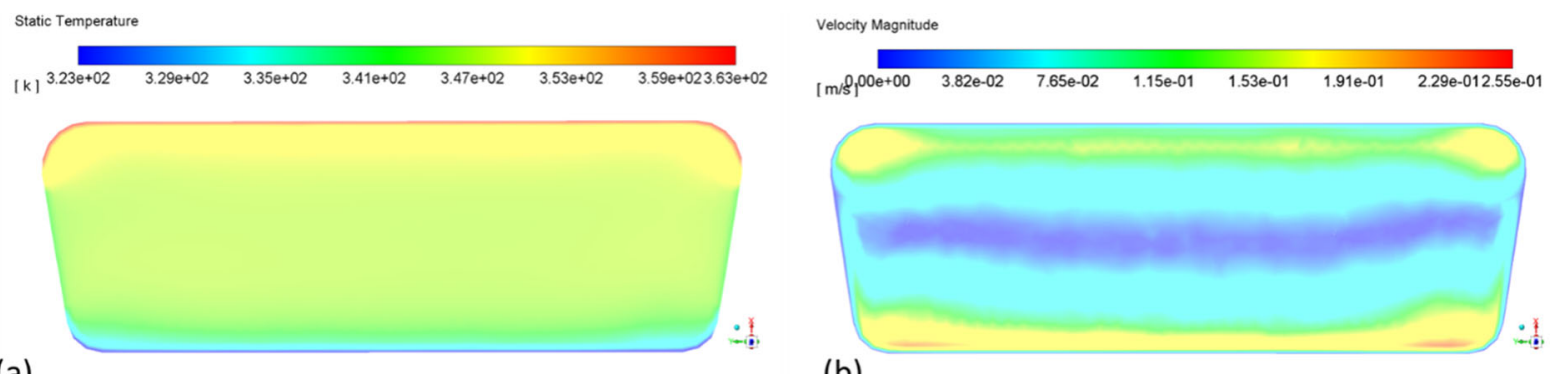

(a)

\section{(b)}

Fig. 7 Tyre RANS simulation at $\omega=0 \mathrm{rad} / \mathrm{s}$. Temperature (a) and velocity (b) contours in the tyre cross section
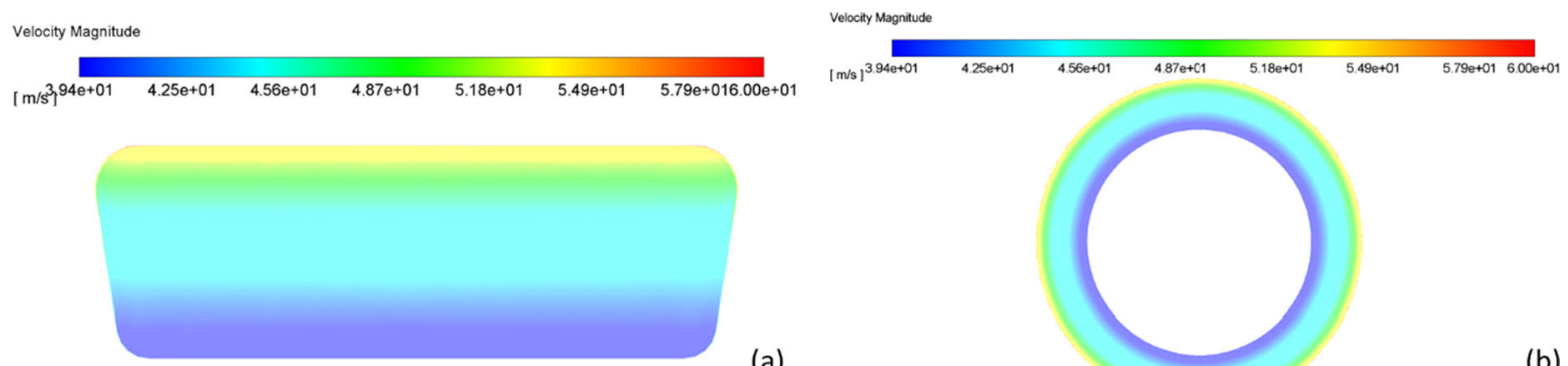

(a)

Fig. 8 Tyre RANS simulation at $\omega=0 \mathrm{rad} / \mathrm{s}$. Velocity vector distribution in a longitudinal tyre section

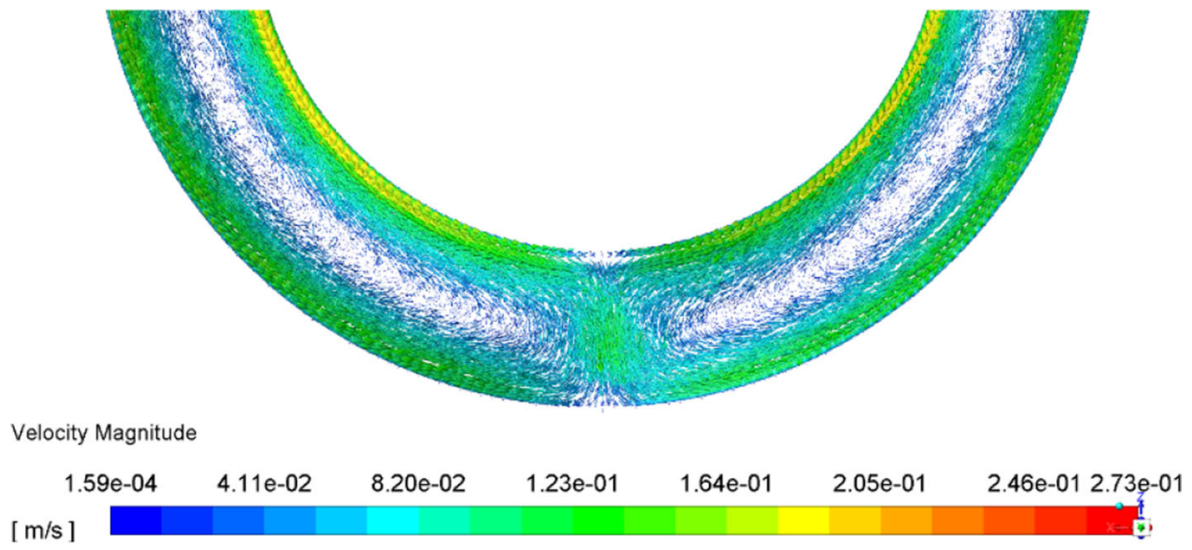

Fig. 9 Tyre RANS simulation $\omega=187,5 \mathrm{rad} / \mathrm{s}$. Velocity contour in cross section (a) and in longitudinal section (b) of the tyre

shows the computed linear trend of convective heat transfer coefficients by varying the tyre angular velocity. Low values are reached at null angular velocity, due to the low natural convective heat exchange mechanism.

As expected, the convective heat transfer coefficient shows an increasing trend with the tyre angular velocity. Indeed, at increasing angular velocity the convective heat exchange at relevant tyre walls (i.e. rim and inner liner) is enhanced thanks to the higher turbulence level in the orthogonal direction to the walls.

The convective heat transfer coefficient profiles computed by 3D CFD simulations is the result that will be used to refine the $3 \mathrm{D}$ tire model. It represents the numerical prerequisite for the estimation of tyre thermal behaviour by employing a refined 3D model discussed in the next section. 
Fig. 10 Tyre RANS

simulation at $\omega=187,5 \mathrm{rad} /$

s. Velocity vector

distribution

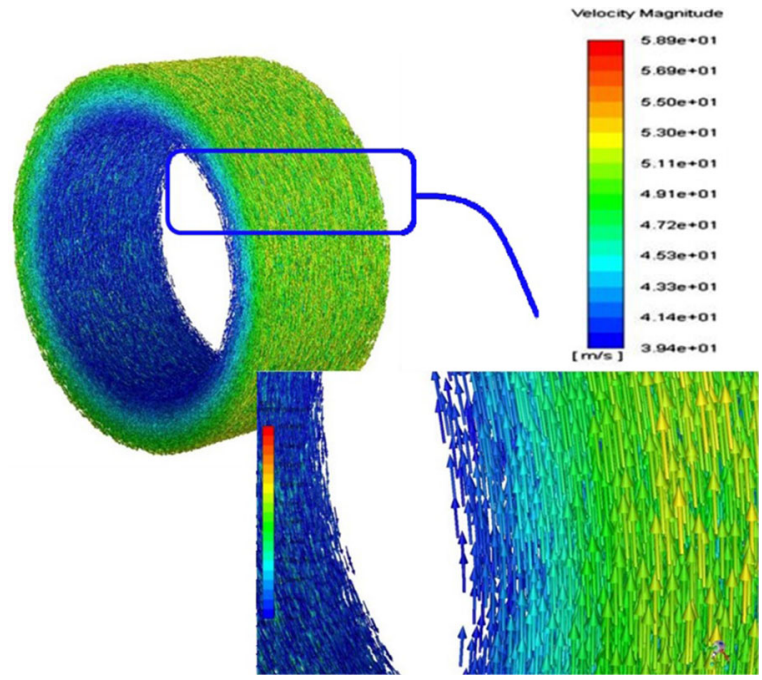

addressed comparing full three-dimensional model towards a simplified grid configuration. In [20] the authors have included the sidewalls and the wheel rim within the tyre model node layout, which represents the final model configuration adopted for this work. Since the thermal model can be employed for both the offline Software-in-the-Loop routines for vehicle performance analyses and the online hard real-time Driver-in-the-Loop applications, the number of nodes $n$ can vary, depending on the particular tyre geometry under the investigation (motorsport, truck/bus or passenger tyre) and on the presence of eventual additional thermal sources (brakes, specifically designed cooling and warming systems or diffusers) to be considered, as addressed by the authors in $[17,20]$. At the current stage, the average thermal model configuration of requires $0.0004-0.0005 \mathrm{~s}$ on the average Xeon simulator machine (150 nodes for a motorsport/passenger tyre and 180 nodes for a truck/ bus tyre, respectively) for each computational step. In this configuration, the model is hard real-time capable for the use, where the tyres thermodynamics, kinematics and dynamics and the vehicle state are computed simultaneously in real-time, since the typical frequency used within the simulator automotive environments is $1 \mathrm{kHz}$ and the same mesh is adopted for both off-line and real-time environments. 
The tyre thermal model is based on the Fourier diffusion equation applied to a three-dimensional heterogeneous domain:

$$
\begin{aligned}
\frac{\partial T}{\partial t} & =\frac{\dot{q}_{G}}{\rho \cdot c_{v}}+\frac{1}{\rho \cdot c_{v}} \\
& \times\left(\frac{\partial^{2} k(x, y, z, T) \cdot T}{\partial x^{2}}+\frac{\partial^{2} k(x, y, z, T) \cdot T}{\partial y^{2}}+\frac{\partial^{2} k(x, y, z, T) \cdot T}{\partial z^{2}}\right)
\end{aligned}
$$

where

- $\dot{q}_{G}$ is the energy generation rate per unit volume $\left(\mathrm{W} / \mathrm{m}^{3}\right)$;

- $\quad \rho$ is the density of material $\left(\mathrm{Kg} / \mathrm{m}^{3}\right)$;

- $c_{v}$ is the specific heat of material $(\mathrm{J} / \mathrm{KgK})$;

- $k$ is the thermal conductivity of material $(\mathrm{W} / \mathrm{mK})$;

- $x, y, z$ are the coordinates of the nodes within the tyre system discretization;

- $T$ is the temperature of the node under analysis $(\mathrm{K})$;

- $t$ is the time (s).

In particular, the thermodynamic non-linear characteristics of different materials have been estimated employing the testing non-destructive methodology described in [44], allowing to estimate the diffusivity characteristics of the tyre tread starting from the acquisitions of the temperature gradients on the tyre external and internal surfaces established as a consequence of the application of a known heating power source and its propagation through the internal layers. The procedure requires two thermal cameras pointed on the opposite sides of the tyre tread, external surface and internal innerliner, acquiring the temperatures in radial and circumferential directions. The non-linear diffusivities are determined applying boundary conditions of a specifically designed testing procedure [44], solving a minimization iterative problem between the model temperature outputs and the experimentally acquired ones. Since the material diffusivity parameters are not constant, but they deeply depend on the model thermal state, the diffusivity of each node in each direction of interest will be different per each step: for this reason, the transient phase is particularly important due to higher thermal gradients within the composite structure to accurately identify the tyre node intrinsic characteristics. The equation is generalized per each node of the entire wheel system in Eq. 3, taking into account of the peculiar material characteristics, depending on its position within the three-dimensional grid, so to describe the system 1st differential state in the typical matrix form:

$$
\left\{\begin{array}{c}
\frac{\Delta T_{1}}{\Delta t} \\
\frac{\Delta T_{2}}{\Delta t} \\
\frac{\Delta T_{n}}{\Delta t}
\end{array}\right\}=\left\{\begin{array}{l}
b_{1} \\
b_{2} \\
\cdots \\
b_{n}
\end{array}\right\}+\left[\begin{array}{ccc}
a_{1,1} & \cdots & a_{1, n} \\
\cdots & \cdots & \cdots \\
a_{n, 1} & \cdots & a_{n, n}
\end{array}\right]\left\{\begin{array}{c}
T_{1} \\
T_{2} \\
\cdots \\
T_{n}
\end{array}\right\}
$$

To completely describe the wheel system, as illustrated in Fig. 12, the following physical thermal phenomena are considered:

- Heat generative term at the tyre/road interface due to the tangential interaction (known as Friction Power);

- Heat generative term due to the effect of tyre cyclic deformation during the rolling and of tyre structure deformation due to tangential interaction loads (known as SEL or Strain Energy Loss);

- Heat conductive term within the contact patch area between the rubber compound and the road texture;

- Heat convective term with the external environment due to the tyre external interaction of the tread layer with the outside air;

- Heat convective term concerning the inner air state and its interaction with the surfaces of inner liner, sidewalls and rim;

- Heat convective and radiative terms due to the impact of possible additional fluxes (from additional heating or cooling sources as brakes or exhaust gases diffusers) impacting the wheel rim surface;

- Heat conduction between the different materials constituting the tyre structure.

Focusing on the conductive term within the tyre structure, a three-dimensional configuration reproduces the composite nonhomogeneous structure of different tyre layers (rubber compound, steel belts, plies, etc.) constituting the tyre system, taking into account the diffusivity dependencies on temperature state of each material considered. It must be highlighted that the following modelling hypotheses have been made:

- The road texture is isotropic and homogeneous, without irregularities, so to schematize the tarmac 


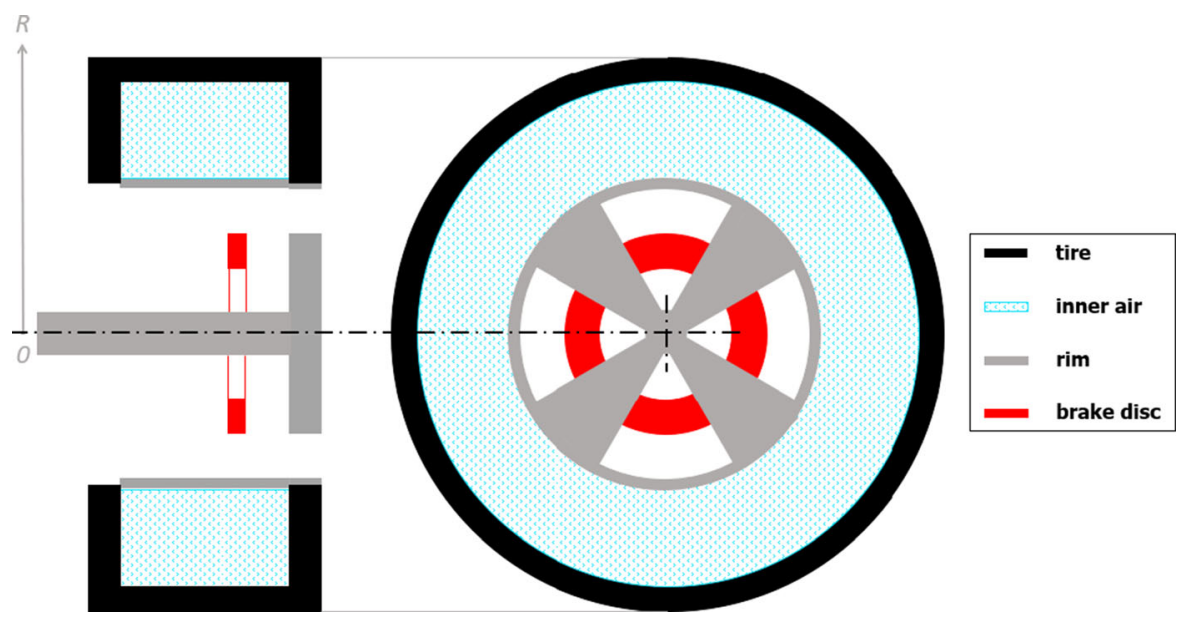

Fig. 12 Thermodynamic model scheme of the wheel

as a geometric plane whose surface temperature is equal to $T_{r}$;

- The tyre tread is modelled as a parallelepiped unrolled in the circumferential direction and discretized in a certain number of ribs only in the lateral direction to take into account of the local friction effects within the contact patch in terms of position and shape as a consequence of the wheel alignment;

- The radiation exchange mechanism of the tyre tread layer is neglected.

Since the purpose of this study is to focus only on the exchanges concerning the inner air fluxes, the model macro-discretization along the radial direction can be summarized as in the Fig. 13, where:
- Node 1: the rubber compound layer constituting the external surface of the tyre where the predominant physical phenomena are the external convection and the thermal exchanges concerning the tyre/road interaction within the contact patch. Regarding the generative thermal term, it has to be highlighted that a specific quantity, called friction factor, evaluated at each time step taking into account of the diffusivity characteristics of the tyre tread compound and the road pavement, is used to correctly split the amount of the energy arising at the tyre-road interface, as described in $[19,20]$;

- Node 2: the rubber compound layer particularly significant to describe the tyre grip and stiffness dependencies towards temperature and pressure effects;

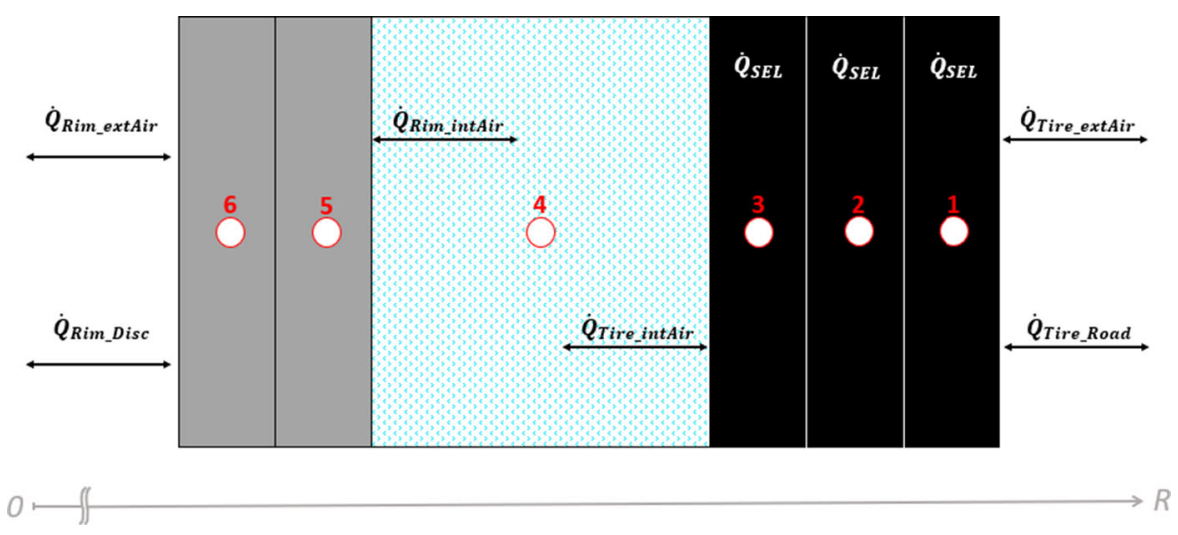

Fig. 13 Simplified representation of the radial thermal flux within the complete wheel system 
- Node 3: the equivalent carcass structure node able to thermodynamically describe the behaviour of the inner tyre layers;

- Node 4: the internal air node involved in convective thermal flows with the tyre inner liner and the rim surfaces (the thermal exchange with the sidewalls' surface is not represented in the figure, but it is considered in the overall thermal model);

- Node 5: the metal alloy rim layer, interacting in the convective thermal exchange with the internal air node;

- Node 6: the external layer of the rim alloy involved in the external convection and radiation terms with the additional components constituting the wheel system, as brakes, diffusers or particular heating/cooling systems.

\section{Results}

The actual dynamic behaviour of tyre can be experimentally investigated through dedicated tests realized with a wide range of methodologies. One of the most reliable is the force and moment bench, also known as Flat-Trac (from the name of the probably most famous bench), able to fully characterize a tyre in working conditions, acquiring also thermal data [45]. As a general remark, various tests can be carried out on the Flat-Trac, mainly thanks to the possibility to control and explore different conditions, including constant or variable angular velocity, internal air pressure, slip ratio, slip angle, camber angle and vertical loads $[45,46]$.

Beyond the wide test potentials, the experimental analyses carried out for the activity were performed at constant angular velocity and internal air pressure, applying low load levels in order to substantially reproduce the undeformed wheel conditions. Such option was selected with the aim to define a proper comparison between the experimental data and the output of the 3D CFD analyses discussed above. Therefore, the setup of the experimental tests was chosen to generate an adequate set of measurements for the validation of the tyre thermal model. The adopted setup of the experimental campaign is listed below:

- Three vehicle velocities: 50, 100 and $150 \mathrm{~km} / \mathrm{h}$;

- Three pressure levels: 0.2, 0.25 and $0.3 \mathrm{MPa}$;
- Three vertical load conditions: 800, 1500, $3000 \mathrm{~N}$.

Beyond the experimental setup here considered, it is the case to stress that the proposed numerical methodology has the potentials to be also applied to higher load cases through a refinement of 3D CFD model to take into account the tyre deformation.

The tyre under investigation was equipped with sensors mainly aiming to measure its temperatures during the experimental tests. Figure 14 summarizes the adopted tyre sensors.

In particular, the so-called TPMS sensor was located on the tyre valve body and utilized to acquire both temperature and pressure of inner-air. A wireless 8 channels sensor ( 8 laser beams) allowed to measure the temperature of the inner liner at different positions. An infrared sensor was adopted to acquire the groove temperature. In addition, a thermal camera was employed to measure the temperature of contact patch. A dedicated data acquisition system (Analog/ Digital CAN Bus) was connected to the above described sensors. As an example, the evolutions of the acquired tyre temperatures are reported in Fig. 15 (b) for the case at constant vehicle velocity of $100 \mathrm{~km} /$ $h$ and at varying both vertical load and internal air pressure.

Similar experimental outcomes are obtained for the other investigated vehicle speeds, but they are not reported and discussed here for sake of brevity.

As depicted in the Fig. 15 (a) three levels of vertical loads $(800,1500$ and $3000 \mathrm{~N})$ are applied to the tyre. For each load, the tyre internal air pressure is modulated in order to explore three different values $(0.2,0.25$ and $0.3 \mathrm{MPa})$. Referring to the temperature profiles, the inner liner measured temperatures at various positions (eight magenta curves in Fig. 15(b) are reported and combined calculating an average temperature profile that will be considered as the reference in the comparison with the corresponding simulation outcomes.

The experimental results presented in Fig. 15 clearly underline that a different tyre thermal regime is experienced according to the internal air pressure level. In particular, for each examined load a lower tyre temperature corresponds to a higher-pressure level. Indeed, at greater tyre inflation pressure the wheel structure becomes more rigid, resulting in less deformation and lower heating effects. Among the 


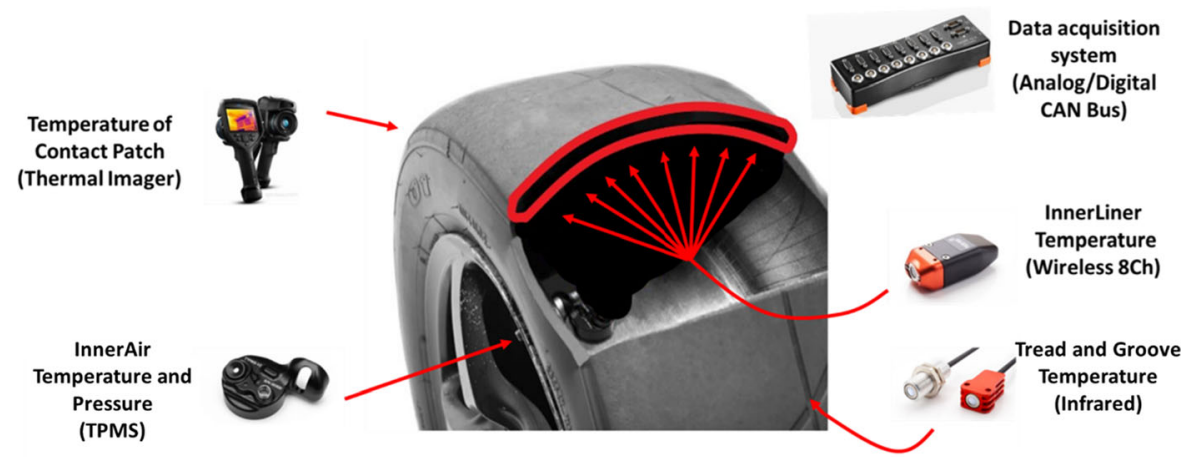

Fig. 14 Tyre sensors employed during tests to measure characteristic temperatures
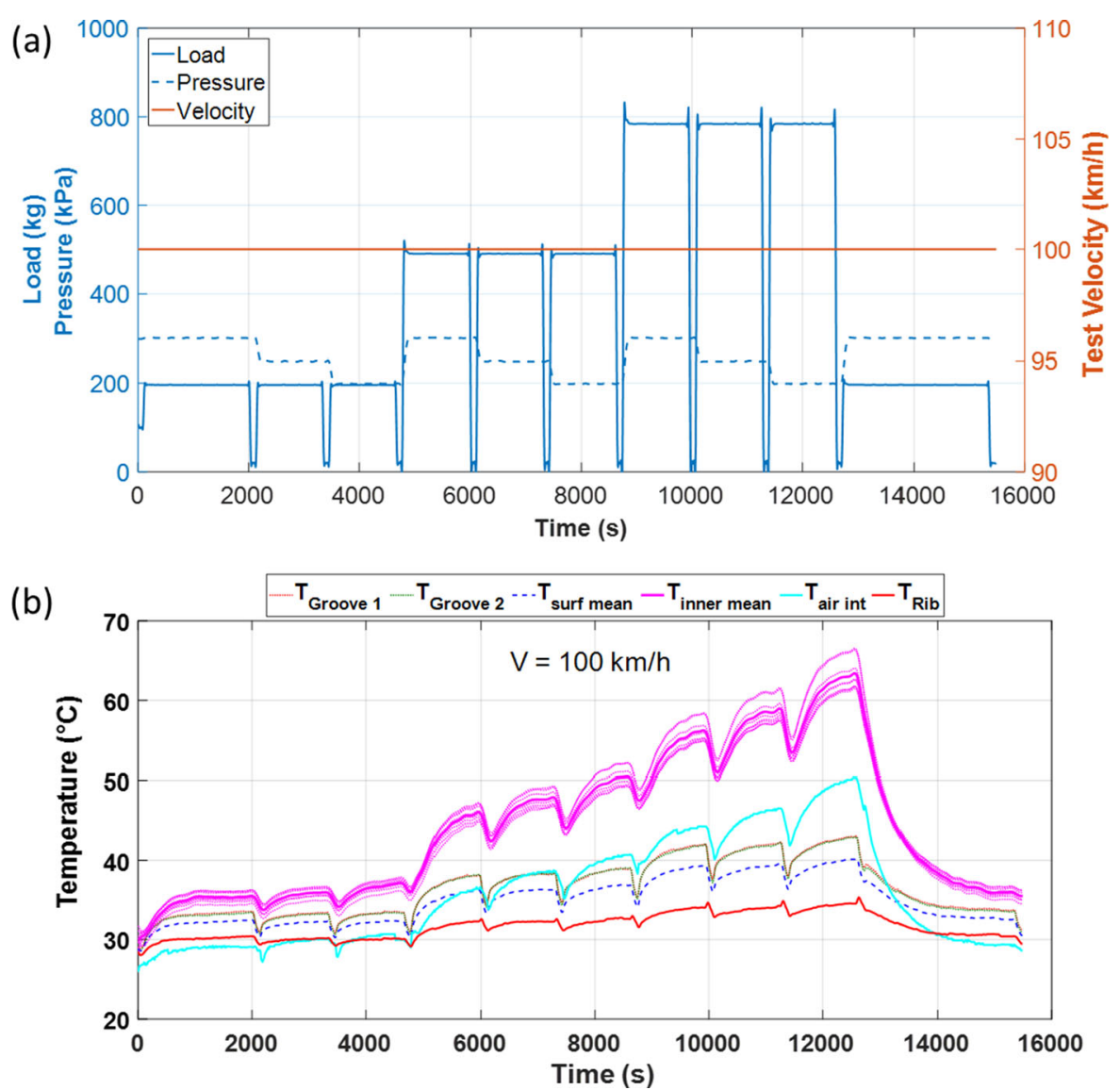

Fig. 15 Temperatures evolution at constant vehicle speed of $100 \mathrm{~km} / \mathrm{h}$, and at varying vertical loads and internal air pressures

investigated vertical loads, the reference condition for the validation of the proposed 3D tyre thermal model is characterized by the load level of $1500 \mathrm{~N}$. This case is representative of a nominal pure rolling condition, with a wheel radius equal to that of the undeformed configuration.
To properly reproduce the experimental conditions, the full thermal tyre model has been fed with the inputs reproducing the experimental setup. As already illustrated, the tyre thermal model is described by a system of n-coupled differential equations (Eq. 3 in state form). In this system, the equation regarding the tyre 
internal air (inner air) is illustrated in Eq. (4), where $h_{\text {Rim }}$ and $h_{\text {InnerLiner }}$ represent the convective heat exchange with the rim and inner liner surfaces, respectively. been compared towards the experimentally acquired analogous quantities, as illustrated in Fig. 15b. In particular, two different simulations have been performed to better highlight the importance of the study

$\frac{\Delta T_{(\text {InAir })}}{\Delta t}=\frac{1}{\rho \cdot c_{v} V}\left[h_{\text {Rim }}(V) A_{\text {Rim,InnAir }}\left(T_{\text {Rim }}-T_{\text {InAir }}\right)+h_{\text {Innerliner }}(V) A_{\text {InLiner,InnAir }}\left(T_{\text {InLiner }}-T_{\text {InAir }}\right)\right]$

The $h_{\text {Rim }}$ and $h_{\text {InnerLiner }}$ have been derived taking into account of the 3D CFD model, as illustrated in Fig. 16, and the estimated temperatures of the innerliner and external tyre surfaces have been compared towards the experimentally acquired temperatures in the same working conditions.

The full thermal tyre model has been fed with the time history channels corresponding to the test routine illustrated in Fig. 15a and the model thermal outputs in terms of surface and innerliner temperatures have conducted, the internal convective exchange coefficient calculated from the analytic formulations available in the literature, as reported in [19, 20], called with the postfix "old" in Fig. 17, and the convective heat transfer coefficient evaluated thanks to the $3 \mathrm{D}$ numerical approach described before. To this aim, the following Fig. 17 shows the model simulated temperature evolutions of the tyre surface and inner liner layers for the same test conditions of the experimental routine described in Fig. 15.
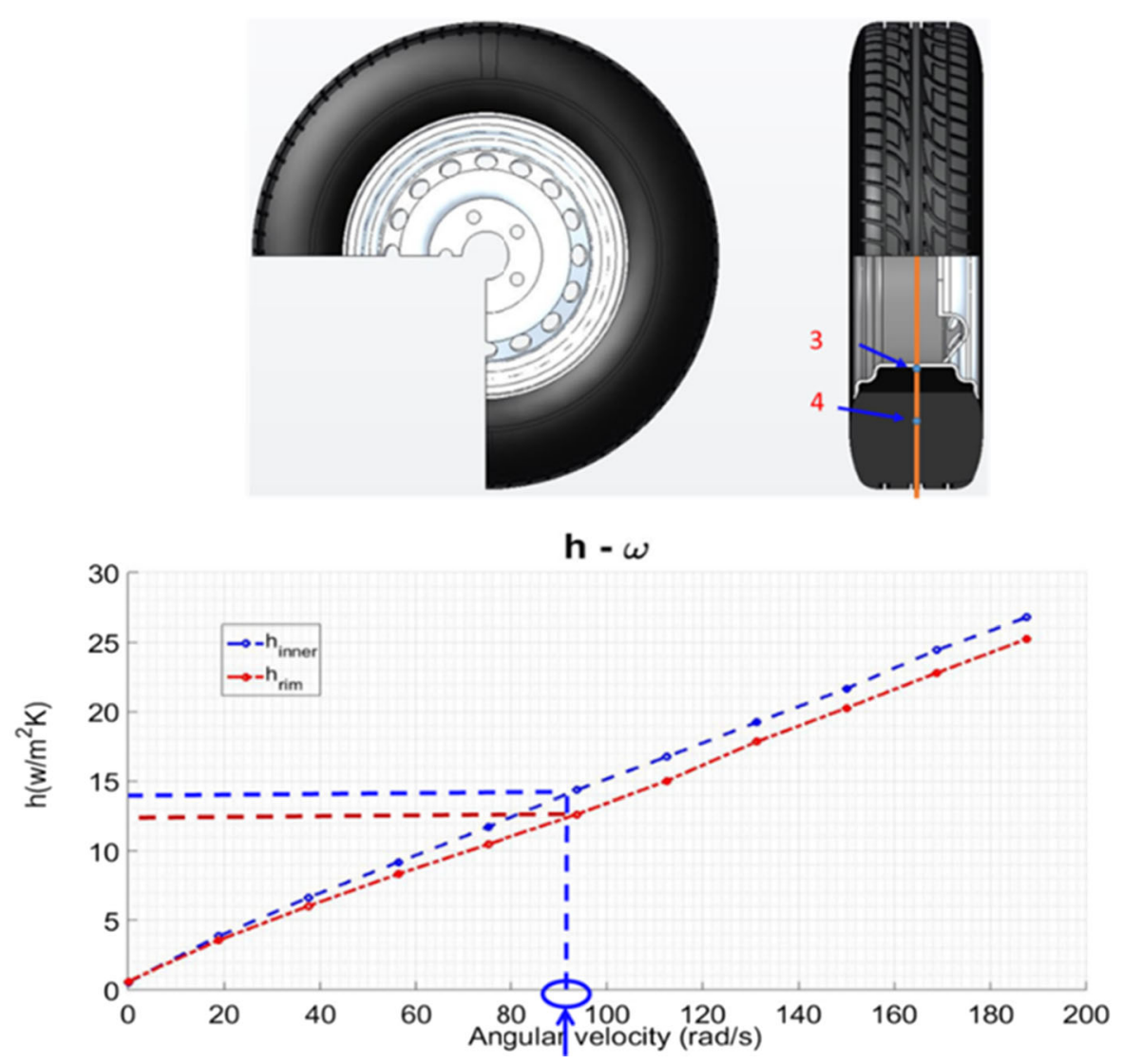

Fig. 16 Integration of 3D CFD derived convective heat transfer coefficients into the full tyre thermal model 


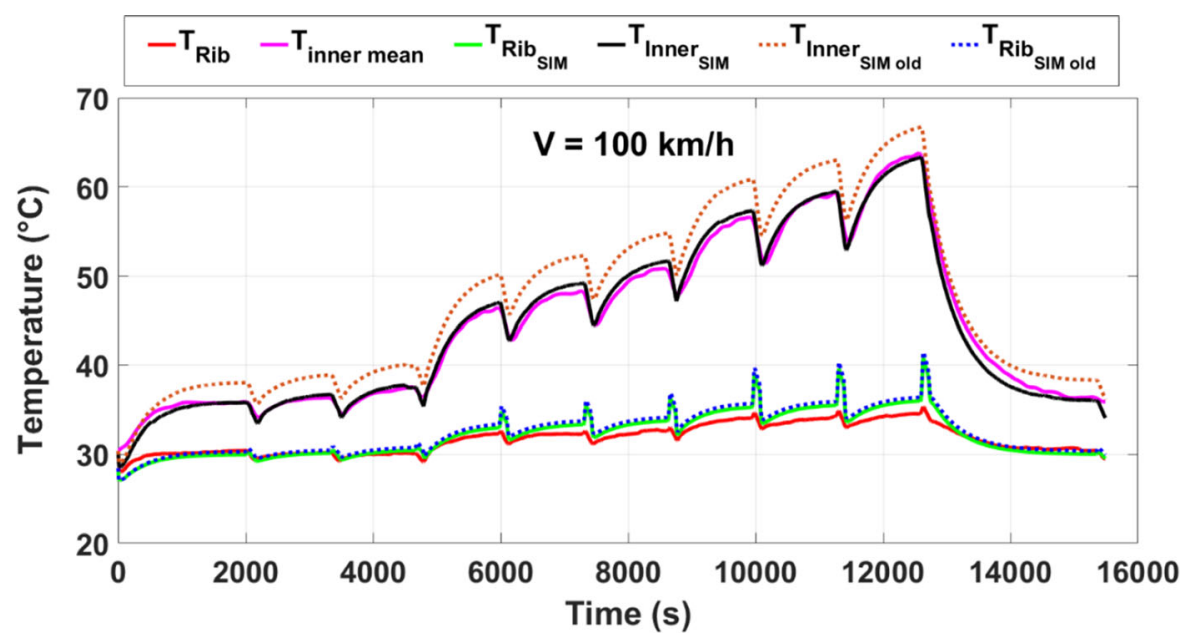

Fig. 17 Numerical vs. Experimental comparison of surface and inner liner temperatures at constant vehicle speed of $100 \mathrm{~km} / \mathrm{h}$, and at varying vertical loads and internal air pressures of tyre

The convective heat transfer effect upon the tyre temperatures is analysed in Fig. 17, where the simulated tyre external and inner liner temperatures are compared to the corresponding experimental quantities in order to validate the developed numerical procedure. A particular attention is devoted to the inner liner temperature since its correct prediction is accountable for a proper modelling of all the physical thermal effects within the tyre structure. In particular, for the considered longitudinal velocity $(100 \mathrm{~km} / \mathrm{h})$ and the test conditions (with variations in loads and pressures), a significant improvement in the numerical/experimental agreement is obtained for the inner liner temperature employing the convective heat transfer coefficient values obtained thanks to the $3 \mathrm{D}$ CFD model. Indeed, the integrated 3D/1D numerical approach allows to improve the predictivity of the full tyre thermal model providing a fast and complete thermal evaluation of all the wheel layers, from rim to the external surfaces.

Similar numerical/experimental agreements for the inner liner temperature are obtained at the other investigated vehicle velocities ( 50 and $150 \mathrm{~km} / \mathrm{h}$ ), but they are not shown here for brevity. The above consideration further highlights the high-level reliability of the proposed methodology.

Summarizing, the presented tyre thermal model, enhanced with 3D CFD derived characteristic convective heat transfer coefficients, is capable to accurately forecast the tyre thermal behaviour under various operating conditions, including variations in vehicle velocity, vertical load and internal air pressure. Since it provides reliable physical predictions at varying tyre working conditions, it can be adopted in a predictive way to explore the tyre thermal behaviour also at conditions differing from those of the discussed validation.

\section{Conclusions and future developments}

The role of the simulations in automotive and motorsport is growing in importance year after year, and tools to predict the vehicle dynamics behaviour are highly requested from a large number of teams in several racing categories.

The reliability of a predictive model is a critical factor in competitions, and it is then fundamental to dispose of a large database of outdoor acquisitions to calibrate and validate the results obtained from a physical model.

As shown above, a quite acceptable predictive level can be assured also employing reduced models with the proper physical modelling, minimizing the number of required parameters, and therefore, the overall cost of the simulation.

This paper presents a numerical procedure consisting of an integrated models able to obtain detailed 3D thermal tyre data to be synthesized into a full wheel thermal model aiming to a fast and accurate description of the thermodynamic tyre behaviour under steady and at varying working conditions. In a first 
stage, a 3D CFD model of the whole system has been realized within ANSYS Fluent environment, considering an undeformed tyre geometry. Preliminary analyses have been carried out to identify the convergence of numerical results at reducing the mesh size, thus demonstrating the reliability of the tyre meshing process.

Steady RANS simulations have been performed at different angular velocities to derive the thermal powers and the convective heat transfer coefficients of each tyre sub-domain. Results confirmed that the thermal powers related to the tyre sidewalls are substantially negligible with respect to ones referring to the inner liner and the rim surfaces. For this reason, the convective heat transfer coefficients of inner liner and rim are considered in the study reported. Indeed, the latter are adopted as input parameters in an advanced and innovative full wheel thermal model, allowing reliable tyre performance predictions combined with reduced computational efforts.

In order to validate the adopted numerical procedure, the outcomes of the tyre model in terms of tyre layers' temperatures have been compared with the measured ones through a dedicated routine realized on the flat trac test bench. Satisfying agreements between numerical and experimental temperatures have been obtained in the whole range of the measured conditions. This result represents a fundamental prerequisite for a proper subsequent tyre performance evaluation and optimization.

In addition, the discussed procedure can be applied for the development of refined control logics concerning the optimal tyre management and the passenger vehicle performance.

As a final remark, some future developments of the proposed modelling approach will be taken into account, including:

- The deformation of the tyre structure to simulate the actual wheel crushing;

- The fluid-structure iteration of tyre to further refine its thermal performance, also including the effects of the external forced ventilation as in the real applications.

Funding Open Access funding provided by Università degli Studi di Napoli Federico II.

\section{Compliance with ethical standards}

Conflict of interest The authors declare that they have no conflict of interest.

Open Access This article is licensed under a Creative Commons Attribution 4.0 International License, which permits use, sharing, adaptation, distribution and reproduction in any medium or format, as long as you give appropriate credit to the original author(s) and the source, provide a link to the Creative Commons licence, and indicate if changes were made. The images or other third party material in this article are included in the article's Creative Commons licence, unless indicated otherwise in a credit line to the material. If material is not included in the article's Creative Commons licence and your intended use is not permitted by statutory regulation or exceeds the permitted use, you will need to obtain permission directly from the copyright holder. To view a copy of this licence, visit http://creativecommons.org/licenses/by/4.0/.

\section{References}

1. Sharp RS, Gruber P, Fina E (2016) Circuit racing, track texture, temperature and rubber friction. Veh Syst Dyn 54:510-525. https://doi.org/10.1080/00423114.2015. 1131308

2. Tuttle JR (2006) Tire temperature and pressure monitoring sensors and systems. United States Pat.

3. Tremlett AJ, Limebeer DJN (2016) Optimal tyre usage for a Formula One car. Veh Syst Dyn 54:1448-1473. https://doi. org/10.1080/00423114.2016.1213861

4. Mohajer N, Abdi H, Nelson K, Nahavandi S (2015) Vehicle motion simulators, a key step towards road vehicle dynamics improvement. Veh Syst Dyn 53:1204-1226. https://doi.org/10.1080/00423114.2015.1039551

5. Ni J, Hu J (2017) Dynamics control of autonomous vehicle at driving limits and experiment on an autonomous formula racing car. Mech Syst Signal Process 90:154-174. https:// doi.org/10.1016/j.ymssp.2016.12.017

6. Mahalingam I, Padmanabhan C (2019) A novel alternate multibody model for the longitudinal and ride dynamics of a tracked vehicle. Veh Syst Dyn. https://doi.org/10.1080/ 00423114.2019 .1693048

7. Liu Y, Hong SK, Ge T (2017) Real-Time Hardware-in-theLoop Simulation for Drivability Development. In: SAE Technical Papers. SAE International

8. Malcher S, Bargende M, Grill M et al. (2018) Virtual Optimization of Race Engines Through an Extended Quasi Steady State Lap Time Simulation Approach. In: SAE Technical Papers. SAE International

9. Février P, Fandard G (2008) Thermal and mechanical tyre modelling for handling simulation. ATZ Worldw 110:26-31. https://doi.org/10.1007/bf03225006

10. Sorniotti A (2009) Tire thermal model for enhanced vehicle dynamics simulation. In: SAE Technical Papers. SAE International

11. Srirangam SK, Anupam K, Scarpas A, Kasbergen C (2015) Development of a thermomechanical tyre-pavement 
interaction model. Int J Pavement Eng 16:721-729. https:// doi.org/10.1080/10298436.2014.946927

12. Rafei M, Ghoreishy MHR, Naderi G (2018) Thermo-mechanical coupled finite element simulation of tire cornering characteristics-Effect of complex material models and friction law. Math Comput Simul 144:35-51. https://doi. org/10.1016/j.matcom.2017.05.011

13. Calabrese F, Baecker M, Galbally C, Gallrein A (2015) A detailed thermo-mechanical tire model for advanced handling applications. SAE Int J Passeng Cars Mech Syst 8:501-511. https://doi.org/10.4271/2015-01-0655

14. Kelly DP, Sharp RS (2012) Time-optimal control of the race car: Influence of a thermodynamic tyre model. Veh Syst Dyn 50:641-662. https://doi.org/10.1080/00423114.2011. 622406

15. Maniowski M (2016) Optimisation of driver actions in RWD race car including tyre thermodynamics. Veh Syst Dyn 54:526-544. https://doi.org/10.1080/00423114.2016. 1158411

16. West WJ, Limebeer DJN (2020) Optimal tyre management for a high-performance race car. Veh Syst Dyn. https://doi. org/10.1080/00423114.2020.1802047

17. Farroni F, Sakhnevych A, Timpone F (2017) Physical modelling of tire wear for the analysis of the influence of thermal and frictional effects on vehicle performance. Proc Inst Mech Eng Part L J Mater Des Appl 231:151-161. https://doi.org/10.1177/1464420716666107

18. Sharifzadeh M, Timpone F, Farnam A et al. (2017) Tyreroad adherence conditions estimation for intelligent vehicle safety applications. In: Mechanisms and Machine Science. Kluwer Academic Publishers, pp 389-398

19. Farroni F, Giordano D, Russo M, Timpone F (2014) TRT: Thermo racing tyre a physical model to predict the tyre temperature distribution. Meccanica 49:707-723. https:// doi.org/10.1007/s11012-013-9821-9

20. Farroni F, Russo M, Sakhnevych A, Timpone F (2019) TRT EVO: Advances in real-time thermodynamic tire modeling for vehicle dynamics simulations. Proc Inst Mech Eng Part D J Automob Eng 233:121-135. https://doi.org/10.1177/ 0954407018808992

21. Kim DJ, Jeong S, Park T, Kim D (2019) Impinging sweeping jet and convective heat transfer on curved surfaces. Int J Heat Fluid Flow 79:108458. https://doi.org/10. 1016/j.ijheatfluidflow.2019.108458

22. Salcedo E, Cajas JC, Treviño C, Martínez-Suástegui L (2016) Unsteady mixed convection heat transfer from two confined isothermal circular cylinders in tandem: Buoyancy and tube spacing effects. Int J Heat Fluid Flow 60:12-30. https://doi.org/10.1016/j.ijheatfluidflow.2016.04.001

23. Chatterjee D, Biswas G, Amiroudine S (2009) Numerical investigation of forced convection heat transfer in unsteady flow past a row of square cylinders. Int J Heat Fluid Flow 30:1114-1128. https://doi.org/10.1016/j.ijheatfluidflow. 2009.09.004

24. Tsuji T, Kajitani T, Nishino T (2007) Heat transfer enhancement in a turbulent natural convection boundary layer along a vertical flat plate. Int J Heat Fluid Flow 28:1472-1483. https://doi.org/10.1016/j.ijheatfluidflow. 2007.04.021

25. Mele B, Russo L, Tognaccini R (2020) Drag bookkeeping on an aircraft with riblets and NLF control. Aerosp Sci
Technol 98:105714. https://doi.org/10.1016/j.ast.2020. 105714

26. Ostieri M, Mele B, Tognaccini R (2018) Linear and nonlinear decomposition of aerodynamic force acting on an oscillating plate. AIAA J 56:594-608. https://doi.org/10. 2514/1.J056129

27. Luigi T, Roberto A, Fabio N (2015) A 1D/3D methodology for the prediction and calibration of a high performance motorcycle SI engine. In: Energy Procedia. Elsevier Ltd, pp 936-943

28. Teodosio L, Pirrello D, Berni F et al (2018) Impact of intake valve strategies on fuel consumption and knock tendency of a spark ignition engine. Appl Energy 216:91-104. https:// doi.org/10.1016/j.apenergy.2018.02.032

29. Teodosio L, De Bellis V, Bozza F (2018) Combined effects of valve strategies, compression ratio, water injection, and cooled EGR on the Fuel consumption of a small turbocharged VVA spark-ignition engine. SAE Int J Engines 11:643-656. https://doi.org/10.4271/2018-01-0854

30. Marais J, Venter G (2018) Numerical modelling of the temperature distribution in the cross-section of an earthmover tyre. Appl Math Model 57:360-375. https://doi.org/ 10.1016/j.apm.2018.01.018

31. Rauh J, Mossner-Beigel M (2008) Tyre simulation challenges. In: Vehicle System Dynamics. Taylor \& Francis, pp 49-62

32. Myshkin NK, Petrokovets MI, Kovalev AV (2005) Tribology of polymers: Adhesion, friction, wear, and masstransfer. Tribol Int 38:910-921. https://doi.org/10.1016/j. triboint.2005.07.016

33. Moore DF (1980) Friction and wear in rubbers and tyres. Wear 61:273-282. https://doi.org/10.1016/00431648(80)90291-4

34. Genovese A, Farroni F, Papangelo A, Ciavarella M (2019) A Discussion on present theories of rubber friction, with particular reference to different possible choices of arbitrary roughness cutoff parameters. Lubricants 7:85. https://doi. org/10.3390/lubricants7100085

35. Pacejka H (2012) Tire and vehicle dynamics. Elsevier Ltd, Amsterdem

36. Guiggiani M (2018) The Science of Vehicle Dynamics: Handling, Braking, and Ride of Road and Race Cars. Springer, Berlin

37. Maas S, Rodarius C, Schmeitz A, Akkermans L, Jansen S (2014) Study on some safety-related aspects of tyre use. European Union Publications Office. https://doi.org/10. 2832/67191

38. Murena F, Mele B (2014) Effect of short-time variations of wind velocity on mass transfer rate between street canyons and the atmospheric boundary layer. Atmos Pollut Res 5:484-490. https://doi.org/10.5094/APR.2014.057

39. Murena F, Mele B (2016) Effect of balconies on air quality in deep street canyons. Atmos Pollut Res 7:1004-1012. https://doi.org/10.1016/j.apr.2016.06.005

40. Menter FR (1994) Two-equation eddy-viscosity turbulence models for engineering applications. AIAA J 32:1598-1605. https://doi.org/10.2514/3.12149

41. Siano D, Teodosio L, De Bellis V, Bozza F (2014) Analysis and design of an intake filter box for a downsized VVA engine. In: SAE Technical Papers. SAE International 
42. Siano D, Bozza F, Teodosio L, De Bellis V (2015) A comparison between external and internal resonators employment to reduce the gas-dynamic noise of a SI engine. SAE Int J Engines 8:42-52. https://doi.org/10.4271/201401-2864

43. Farroni F, Sakhnevych A, Timpone F (2015) An evolved version of thermo racing tyre for real time applications. In: Lecture Notes in Engineering and Computer Science

44. Allouis C, Farroni F, Sakhnevych A, Timpone F (2016) Tire thermal characterization: Test procedure and model parameters evaluation. In: Lecture Notes in Engineering and Computer Science. pp 1199-1204
45. Pottinger MG (1992) Flat-trac II(R) machine, the state-ofthe-art in tire force and moment measurement. Tire Sci Technol 20:132-153. https://doi.org/10.2346/1.2139513

46. Cabrera JA, Ortíz A, Simón A et al (2003) A versatile flat track tire testing machine. Veh Syst Dyn 40:271-284. https://doi.org/10.1076/vesd.40.2.271.16542

Publisher's Note Springer Nature remains neutral with regard to jurisdictional claims in published maps and institutional affiliations. 